\title{
'If it almost kills you that means it's working!' Cultural models of chemotherapy expressed in a cancer support group
}

\section{Kirsten Bell}

NOTICE: this is the accepted version of a work that was accepted for publication in Social Science \& Medicine. Changes resulting from the publishing process, such as peer review, editing, corrections, structural formatting, and other quality control mechanisms may not be reflected in this document. Changes may have been made to this work since it was submitted for publication. A definitive version was subsequently published in Social Science \& Medicine, 2009, volume 68, issue 1, pages 169-176. DOI:

http://dx.doi.org/10.1016/j.socscimed.2008.10.023

\begin{abstract}
It has long been recognised that cancer is an extraordinarily culturally charged disease. However, while studies have provided valuable insights into the embodied experience of cancer, far less research exists on cancer patients' and survivors' perceptions of the treatments they receive and the meanings they assign to these treatments. This paper focuses specifically on chemotherapy - a highly feared form of treatment that is often popularly depicted to be worse than the experience of cancer itself. Drawing on ethnographic fieldwork at a cancer support group in western Canada, this article explores patient perceptions of adjuvant chemotherapy. I argue that a widespread cultural model of chemotherapy exists which emphasises the value of suffering as a means of tracking treatment effectiveness and the possibility of cure. However, while highly coherent, this model diverges from biomedical understandings of treatment in important respects, with implications for patient anxiety levels during treatment and their subjective assessments of the future risk of recurrence. Overall, research findings highlight the need to pay closer attention to the meanings patients assign to cancer treatments and call for further research in this area.
\end{abstract}

\section{Introduction}

It has long been recognised that cancer an extraordinarily culturally charged disease. As Susan Sontag (1977/1990: 5) notes, "Cancer... fills the role of an illness experienced as a ruthless, secret invasion". A body of literature has emerged exploring the rich metaphoric understandings of cancer revealed in the accounts of cancer patients (see Sontag 1977/1990; Gibbs \& Frank 2002; Skott 2002) and oncologists (Good et al. 1990; Penson et al. 2004). Anthropological and sociological studies have also highlighted the gap between biomedical discourses and lay constructions of cancer aetiology and the experience of living with the disease (e.g. Saillant 1990; Balshem 1991; Mathews 2000; Moore 2001; Sinding \& Gray 2005). While these studies have provided valuable insights into the embodied experience of cancer, far less research exists on cancer patients' and survivors' perceptions of the treatments they receive and the meanings they assign to these treatments. 
In other areas, researchers have begun to explore the cultural meanings of treatments and their symbolic significance for patients and providers. For example, the divergent cultural meanings assigned to western medications and their impact on modes of drug use are well documented cross-culturally (Etkin \& Tan 1994; Nichter \& Nichter 1996; Etkin, Ross \& Muazzamu 1999). Moerman's (2002) work on the placebo effect demonstrates the ways in which the cultural meanings connected with medications also influence people's perceptions of their operation and efficacy in the West. Placebo studies have revealed that there is a great deal we 'know' about medicines, even in the absence of evidence. We know that injections are more powerful than pills, very tiny pills are more powerful than aspirin-style pills, and red pills are stimulants and blue pills are depressants $^{1}$ (Moerman 2002: 53). This knowledge about medications (most of which is scientifically inaccurate) stems from an overarching cultural model which dictates that small pills must be super-powerful because of their tiny size, red is a symbolically 'hot' colour and blue a 'cold' colour, etc.

These cultural attributes influence our understandings of how such pills operate knowledge that is readily manipulated by pharmaceutical companies. In one of the few available studies exploring chemotherapy drugs, Abel \& Glinert (2008) found that drug names contain a high frequency of sounds associated with lightness, smallness and fastness. They concluded that this may, in turn, encourage patients and providers to perceive the drugs as "fast-acting" and "less invasive" (p. 1867). Although Abel and Glinert do not actually explore perceptions of chemotherapy amongst patients, their research does raise interesting questions about how such drugs are perceived - especially given the "psychologically charged" nature of this form of treatment (p. 1864).

Films such as the Julia Roberts vehicle Dying Young graphically depict the side effects of chemotherapy, which one of the principal characters refers to as "poison" (Clark 1999). According to Clark (1999), moviemakers and audiences without direct experience of chemotherapy are likely to be strongly influenced by such representations. Indeed, through such films we collectively 'know' that chemotherapy is a terrible experience, as bad - worse even - than the experience of cancer itself. The pervasiveness of this cultural 'fact' has been verified in several studies and research has shown that noncancer, chemotherapy-naïve patients tend to over-estimate the impact of chemotherapy on quality of life, relative to patients actually in chemotherapy (Lindley et al. 1999: 63). For patients with cancer, the prospect of chemotherapy is accompanied by high levels of fear and anxiety (Abel \& Glinert 2008; Cowley et al. 2000; Browall et al. 2006; Frith \& Harcourt 2007; Frith, Harcourt \& Fussell, 2007).

In light of the very powerful imagery that chemotherapy evokes, and the high level of fear that cancer patients experience prior to treatment, it is surprising that it has not been the focus of more research. Unfortunately, there is very little available research on patients' perceptions of treatment and how they understand it to actually operate, although two areas of related inquiry have begun to emerge. First, a small body of research explores patients' attitudes towards adjuvant chemotherapy and the ways this influences their decision-making preferences regarding treatment (Charles et al. 1998; Jansen et al. 2001; Stiggelbout \& Haes 2001; Jansen et al. 2005). This research has 
revealed that patients generally perceive adjuvant chemotherapy as a necessary step in minimising the possibility of future recurrence (Charles et al. 1998), even in contexts where the benefits are deemed to be extremely small or clinically non-existent (see Jansen et al. 2001; Duric et al. 2007).

Another group of primarily qualitative studies focus more directly on patients' experiences of chemotherapy, highlighting the physical and emotional suffering associated with it (Beisecker et al. 1997; Cowley et al. 2000; Richer \& Ezer 2002; Browall et al. 2006). Other related studies focus on the ways in which treatment side effects (particularly hair loss) affect patients' perceptions of their appearances (see Frith \& Harcourt 2007; Frith, Harcourt \& Russell 2007; Rich \& Ezer 2002; Rosman 2004). This research reveals that the overwhelming majority of patients do not regret the decision to undergo adjuvant chemotherapy and would make the same treatment choice again, despite the suffering entailed (Beisecker et al. 1997). However, few available studies set out to explore how cancer patients perceive chemotherapy to exert its effects and the implicit understandings they develop regarding this form of treatment. Patients' knowledge about how chemotherapy works is a "construction laid atop the world of experience" (c.f. Moerman 2002: 67) and it is therefore likely that lay understandings of chemotherapy differ significantly from biomedical treatment models.

This article will provide a preliminary exploration of patient perceptions of chemotherapy. Drawing on data from a larger ethnographic study of cancer support groups, I explore the ways that members of a cancer support group talk about chemotherapy. Through excerpts from both fieldnotes and ethnographic interviews, I seek to highlight the understandings of chemotherapy expressed in the group and the ways these understandings diverge from biomedical models of treatment.

\section{Research Setting}

The setting was a professionally-facilitated, drop-in support group for colon and rectal cancer patients and caregivers held at a cancer treatment centre in Western Canada. While the group hosted occasional guest speakers, for the most part, the monthly meetings (1.5hrs) consisted of a process of 'checking in', whereby participants updated fellow members on how they were doing. Although the group had a fluctuating membership, during the 8-month fieldwork period (September 2007-April 2008) there were, on average, 10 people present at the monthly meetings. This figure included the 6 core members in the group, along with a revolving door of irregular and one-time attendees (see table 1 for an overview of participant characteristics). The existence of an unchanging core membership meant that there was substantial continuity in the meetings over time, despite the drop in format of the group. ${ }^{2}$ 
Table 1. Characteristics of Support Group Participants

\begin{tabular}{|c|c|c|c|c|c|c|}
\hline \multirow{2}{*}{ Characteristics } & \multicolumn{2}{|c|}{ Regulars } & \multicolumn{2}{|c|}{ Sporadic Participants } & \multicolumn{2}{|c|}{ One-timers } \\
\hline & $\mathrm{n}$ & $\%$ & $\mathrm{n}$ & $\%$ & $\mathrm{n}$ & $\%$ \\
\hline \multicolumn{7}{|l|}{ Sex } \\
\hline Female & 4 & $67 \%$ & 7 & $64 \%$ & 5 & $38 \%$ \\
\hline Male & 2 & $33 \%$ & 4 & $36 \%$ & 8 & $62 \%$ \\
\hline \multicolumn{7}{|l|}{ Ethnicity } \\
\hline White & 6 & $100 \%$ & 10 & $91 \%$ & 11 & $85 \%$ \\
\hline Chinese & & & & & 2 & $15 \%$ \\
\hline South Asian & & & 1 & $9 \%$ & & \\
\hline \multicolumn{7}{|l|}{ Category } \\
\hline Patients & 5 & $83 \%$ & 8 & $67 \%$ & 8 & $62 \%$ \\
\hline Caregivers & 1 & $17 \%$ & 3 & $33 \%$ & 5 & $38 \%$ \\
\hline \multicolumn{7}{|c|}{ Treatments received } \\
\hline $\begin{array}{l}\text { Adjuvant } \\
\text { chemotherapy }\end{array}$ & 3 & $60 \%$ & 6 & $33 \%$ & 8 & $100 \%$ \\
\hline $\begin{array}{l}\text { Palliative } \\
\text { chemotherapy }\end{array}$ & 1 & $20 \%$ & 2 & $22 \%$ & 0 & $0 \%$ \\
\hline \multicolumn{7}{|l|}{ Status } \\
\hline In treatment & 1 & $20 \%$ & 4 & $50 \%$ & 4 & $50 \%$ \\
\hline Post-treatment & 4 & $80 \%$ & 4 & $50 \%$ & 4 & $50 \%$ \\
\hline
\end{tabular}

\section{Methods}

Participant observation was conducted at monthly cancer support group meetings $(\mathrm{N}=8)$, as well as other activities connected with the group, such as a day-long retreat and a colorectal cancer information forum. Observational data were recorded as fieldnotes following the group meetings. As it is generally uncommon to have nonparticipants take part in cancer support groups (Mathews 2000), I would like to comment briefly on the context of the fieldwork. This particular support group was open to patients, caregivers and "their supporters", and occasional observers would sit in on group meetings. ${ }^{3}$ Thus, the presence of an 'observer' was not completely alien to the group. The general perception of colorectal cancer as an under-researched and resourced cousin of breast and prostate cancer also meant that group members viewed the research very positively.

In group meetings, I observed without participating unless asked a direct question. However, this venue provided numerous opportunities to converse and interact with group participants informally. My involvement as a more active participant in other events connected with the group, such as the retreat, the colorectal cancer forum, and a fundraising event for below-the-belt cancers, also helped to establish my status as an 'honorary' group member. Thus, while my presence no doubt had some effect on the group, I think that the connections I developed with group members (which are ongoing), along with my participation with the group over time, helped to minimize the intrusive aspects of my observation.

Aside from the participant observation at the support group meetings, in-depth, semistructured interviews were conducted with 8 group members: 5 of the regular members of 
the group, 1 person who attended the group sporadically and a further 2 people who attended only once. With the consent of participants, all interviews were recorded and transcribed verbatim. Interviews covered basic questions about people's diagnosis with cancer, their experience of cancer treatments and the support group itself. To facilitate data analysis, all references to chemotherapy in fieldnotes and interviews were extracted and subject to thematic analysis with the aid of the qualitative software program NVivo.

\section{Findings}

\section{Overview}

The side effects of chemotherapy were the most common topic of discussion in the support group meetings throughout the fieldwork period. Although many of the group members were no longer in active chemotherapy, many ( 8 of 10 people) were continuing to deal with the ongoing side effects of treatment - with residual chemo-induced peripheral neuropathy (CIPN) a key issue for most post-treatment survivors. However, not everyone experienced difficulties during chemotherapy. One woman, Victoria (all names are pseudonyms), had relatively few side effects from her intravenous chemotherapy and another attendee, Barry, also expressed surprise at how uneventful his oral chemotherapy had been to date. While these participants were often reminded of the cumulative effects of chemotherapy and that their symptoms were likely to worsen over time, several group members such as Victoria remained relatively symptom-free throughout their full course of treatment.

Hurting the good cells \& really hurting cancer cells

An idea that was commonly expressed in the support group was that if chemotherapy is hurting and causing side effects, this is evidence of its increased efficacy. Importantly, such assertions were made in group contexts where they seemed to reflect a broader consensus about the nature and operations of chemotherapy. As the following examples reveal, these statements were uncontested and were generally offered either as hypotheses regarding the mechanisms of chemotherapy or as simple statements of fact.

At one support group meeting with 12 participants present, a guest lecture on naturopathy and the effectiveness of various natural products in treating cancer is presented. After the lecture the following exchange was recorded in my fieldnotes:

Joanne asks whether it is okay to take these products during chemotherapy, as she has been was advised not to take any supplements while undergoing treatment.

The naturopath emphasises that people need to be careful about the products they take during chemotherapy. Pam notes that when you're on chemo you've only got 'one shot' so you want to make sure you get 'a 100\% dose - as you can't go back and get the extra 30\% later'; the assembled group nods. Jack then offers that he figures that when chemo hurts him, it must be 'really hurting the cancer cells'.

At another group meeting with 13 people present, during 'check in' a discussion arose about the side effects of chemotherapy, which was recorded in my fieldnotes as follows: Bob mentions that he thinks it is pretty bad that one of the standard chemo drugs [5-FU] is quite archaic and has been around for 20 years. 'Surely we can do better than that!' he comments. He continues that although his chemotherapy was 
difficult, he is doing very well now, aside from the neuropathy which 'I can't complain about'. Victoria asks him some further questions about the neuropathy and Maria, a first-time attendee in the group, asks what neuropathy is. After Bob explains, Victoria wonders whether her chemo is actually effective because she is not experiencing many side effects and she has heard that the more side effects you have, the better it is working.

When Victoria completed her treatment this issue continued to be a source of anxiety for her. At a group meeting with 11 people present, when it was Victoria's turn to 'check in', she expressed the following sentiments:

Victoria announces that she finished chemotherapy three weeks ago and is surprised at how quickly she has bounced back. She continues that as many of us know, she had a very 'easy time' of chemotherapy - although she notes [in relation to an earlier comment that someone is feeling ambivalent about treatment] that she started to get discouraged about half way through because there didn't seem to be any end in sight. Victoria then says that she had such an 'easy time' of chemo that she feels she must be cured. However, she also worries that it was 'too easy' and that she might be 'blindsided' by a cancer recurrence. At this point she starts to cry and seems to want reassurance from other participants in the group that the cancer will not return.

On another occasion, during a day-long retreat which 14 group members attended, a conversation occurs over lunch about people's experiences with chemotherapy. The exchange was recorded in fieldnotes as follows:

Ann indicates that sometimes she feels like she has to apologise because she had oral chemo. She had one friend tell her 'well, I take vitamins, too'. Ann goes on to say that while she doesn't think of her chemo as being that bad, when she looks through her journal she is surprised to remember that things were worse than she recalls. We then talk about how everyone's experience of chemo and radiotherapy is different and I mention that I have heard some people say that they had a worse time with radiation than chemo. Rowena, fresh from her own experience of chemotherapy, cries 'chemo is no picnic!' She tells us that she had to be hospitalised because she got so sick from her chemo that she 'almost died'. Rochelle then comments, 'So it must have been working!'

\section{Getting a 'full dose'}

For a variety of reasons cancer patients often do not receive their scheduled number of chemotherapy treatments, because of low blood counts, and other treatment side effects and complications, etc. This was a source of considerable stress for a number of members of the group. Importantly, while such delays caused marked distress during treatment, they continued to be a source of concern following the successful completion of treatment. Pam's previously mentioned assertion about the need to get a " $100 \%$ dose" was echoed in a number of individual interviews. One woman, Mary, who was still undergoing chemotherapy at the time of the interview, described her previous experience of chemotherapy delays as follows: 
Mary: Well, actually they had to delay the treatment for a week, because I was so dehydrated.

KB: Okay, so with the second chemo they had to delay it. How did you feel when they had to delay the chemo?

Mary: Scared.

KB: Okay. So why did you feel scared?

Mary: I said to her [the oncologist] 'Well is this going to make the cancer grow faster or...?' She said 'No, we have to delay it, your health is at risk'...

KB: Right. Now with the chemo, and so just to clarify, you said that she said that 'I'll give you more chemo but only if you agree to lowering the dose'. How do you feel about...?

Mary: Well I said, 'Does that give me the optimal benefit?' And she said 'They've lowered lots of people' and that's what she answered.

A similar exchange occurred with Joanne, who was also undergoing chemotherapy at the time of the interview:

KB: So what about the chemo? Can you tell me a little bit more about when you started chemo and how the chemo's been for you?

Joanne: Yeah, sure... The first one was the worst... Then the second one was delayed because my white [blood] count was low, and I wasn't expecting that either... I was disappointed because I thought, you know, 'how can that be?'... And then there was the wait and I was getting, you know, like 'Please just give it to me'... But the chemo, now that I have it I'm much happier, being on the chemo, and so yeah, the second time, the white count was like 1.3 and the cutoff was $1.5 \ldots$

KB: Oh, so you were just under.

Joanne: I was just under. And then the research nurse said to me 'Oh well, if you weren't in the trial [Alison is involved in the standard arm of a clinical trial] they would have given it to you.' And I'm like 'What!' So then I thought, you know, because I was worried - even though they say it doesn't matter if you delay it one week, what if it does?...

These concerns about receiving a lowered chemotherapy dose because of unexpected delays in chemotherapy were also voiced by post-treatment survivors who had successfully completed treatment. Another member of the group, Bob, reflecting back on his treatment commented,

Bob: You know, he [the oncologist] had told me, I guess the last time I saw him that, because I was asking, because I was denied my last two treatments because I ran out of time on my clinical trial because of delays that I had had, so I felt like I was short changed to get all the medicine, if you will. And so I quizzed him about that and I, you know, was asking what effect that would have, missing those last two treatments. And he explained to me that in the research collected so far, really it made no difference. 
Oral vs. intravenous chemotherapy

Another notable feature of the support group was a difference in the way that oral and intravenous chemotherapy were perceived. Although few members of the group had received oral chemotherapy, those who received it emphasised its diluted potency in relation to intravenous chemotherapy. On one occasion, a first-timer to the meeting, Barry, stated that his oral chemotherapy was like taking an "aspirin". As previously noted, one of the group regulars, Ann, told the group that she sometimes feels like she has to apologise because she had oral chemotherapy. When she later elaborated on this in an in-depth interview, it became clear that she, too, had originally made a correlation between the oral form of the chemotherapy and a diluted dose.

Ann: Even though I feel that mine [her cancer] was probably - this is how I rationalise it - well, mine wasn't that bad because I only got Capecitabine [an oral chemotherapy agent], so therefore if you have intravenous it must be worse, but I'm thinking stage 3 is stage 3 so I don't know how it could be better or worse... Somehow I feel that I'm almost apologetic for it, you know. And yet I always remember Jack saying he went on it and he almost had a coronary on it. He was so ill that they had to get him off it right away.

\section{Discussion}

The idea that suffering increases efficacy was a key motif in discussions of chemotherapy in the support group. Importantly, this equation is also evident in accounts of chemotherapy expressed beyond the confines of the group. For example, a previous study on perceptions of the side effects of chemotherapy amongst breast cancer patients (Rosman 2004: 336) reports in passing that: "In certain cases the level of [hair] loss is directly related to the presumed strength and effectiveness of the treatment. The greater the loss the more effective the treatment seems to be, so the confidence in being cured increases." Several community-based cancer organisations also explicitly address this misconception in their resources for cancer patients (CCS 2007; Breastcancer.org 2008). For example, in its "myths about chemotherapy" section, Breastcancer.org (2008) notes: "There is no correlation between the amount that someone suffers from chemotherapy and the benefit it has against the cancer. Everyone responds differently". The fact that they have chosen to address this "myth" at all would suggest that it is widespread.

Despite the pervasiveness of this equation between toxicity and efficacy, from a biomedical perspective toxicity does not necessarily equal gain. Although intentionally underdosing below standard levels leads to both reduced toxicity and reduced benefit (Gurney 2002), the side effects of standard chemotherapy treatments are highly variable and dependent on a variety of factors (see Repetto 2003; Lemare et al. 2007). For most cancers there is a plateau in the chemotherapy dose-response curve: while increasing the dose above a standard cut off increases toxicity it does not improve anti-tumour effect (Gurney 2002). Given that toxicity does not necessarily equal gain, why is this belief so pervasive amongst patients?

As previously noted, chemotherapy is a form of treatment that is culturally as well as medically prefigured as inducing considerable suffering. It is somewhat unique in that the treatment itself is defined as the source of the suffering. Thus, as Greer (1984) points 
out, chemotherapy would appear to contradict the cardinal principle of medical ethics: primum non nocere (first, do no harm). In contemporary oncology this dictum is taken to mean that the benefits of treatment must be greater than the suffering which it may entail. Certainly, research has demonstrated that systemic chemotherapy in the adjuvant setting improves the curative rate for many patients with localised cancers (on colon cancer see Labianca et al. 2007; Sun \& Haller 2005; Hayden 2003; Maughan 2001). However, while improvements in survival are apparent at a population level, the individual chances of recurrence remain highly uncertain. Indeed, this sense of uncertainty about the reality of 'cure' is the defining feature of the lives of many post-treatment survivors (Mullan 1985; Sinding \& Gray 2005; Magee \& Scalzo 2006). Thus, despite the tribulations of chemotherapy, whether its benefit will ultimately outweigh the suffering it entails is unknown.

I would suggest that this suffering, so central to the experience of chemotherapy, is never merely understood as a medical 'side effect' of treatment. As Kleinman (1988: 30) notes, suffering is not easily put aside by biomedicine. Thus, while biomedicine is largely limited to "rational-technical manipulations aimed at controlling practical problems" the cultural significance of suffering remains fundamental to the experience of treatment, "in spite of professional (and societal) attempts to expunge meaning and value from the equation of care" (Kleinman 1988: 30). This need for suffering to have meaning is starkly illustrated in David Rieff's recent memoir regarding the death of his mother, Susan Sontag. He writes:

I knew that for her the physical agony she was undergoing — and I am not being even slightly hyperbolic when I use those words - was only bearable because of this hope [of survival] and that therefore my task had to be to help her as best I could to go on believing that she would survive. For me to have behaved in any other way would have meant saying to her, in effect, 'your sufferings are for nothing'... (Rieff 2008: 103-104).

For many patients experiencing the rigours of chemotherapy in a context of unclear outcome, suffering becomes meaningfully transformed into evidence of efficacy. When a patient experiences side effects, this is interpreted as visible evidence that the treatment is working. I am not suggesting that treatments producing less toxicity are invariably perceived as deficient or that patients prefer more toxic forms of treatment. My point is that for those people who do experience substantial side effects, these may be constructed as evidence of treatment efficacy because of the need for suffering to take on meaning and purpose. However, research findings do suggest that the centrality of suffering to the experience of chemotherapy may cause concerns for those patients who do not experience it. Thus, while side effects cause significant distress, a lack of side effects may also cause considerable (if less recognised) anxiety.

This counter-intuitive response to what might be considered a positive outcome (in this case, low toxicity) has also been noted in a previous study. In early research on factors contributing to emotional distress during cancer chemotherapy (Nerenz, Leventhal \& Love 1982), contrary to their expectations, the researchers found that participants in the 
study often became particularly distressed after palpable disease signs had disappeared. As Nerenz, Leventhal and Love (1982) explain:

When the disease is directly palpable, it has definite size, shape, consistency, and location. Changes in disease status can be directly and objectively monitored so that even an increase in size of palpable nodes can be processed objectively. When the disease is not palpable, however, there is no way to control such emotional states as fear or anxiety about spread of the disease by resorting to objective indices of its change (p. 1026; emphasis mine).

Similarly, side effects become seen as a way of monitoring the overall effectiveness of chemotherapy. The absence of side effects therefore creates uncertainty about whether the treatment is working effectively. This is precisely what we see in the case of Victoria, who continued to question whether her treatment was working because of her lack of side effects, expressing ongoing anxiety about this throughout and following the completion of her treatment. Indeed, Victoria explicitly connected her "easy" time of chemotherapy with the possibility of future recurrence.

Connected with this idea that side effects provide visible evidence of efficacy is a strong concern with obtaining a full treatment dose. However, the knowledge that $100 \%$ of the treatment dose must be received in order for the treatment to exert maximum effectiveness is also not entirely biomedically accurate. There is evidence that dose reductions or treatment delays may reduce the efficacy of adjuvant chemotherapy for a number of cancers, including colon cancer. However, while the standard of care for the adjuvant treatment of locally advanced (stage III) colon cancer is Fluorouracil (FU)based chemotherapy administered for six months, few studies have explored the prevalence and effects of early termination, and a consensus regarding the optimal doseintensity does not presently exist (Neugut et al. 2006).

Evidence has existed for a decade that six months of standard 5-FU therapy for colon cancer is as effective as twelve months of chemotherapy (O'Connell et al. 1997). Importantly, the benefit of six monthly cycles was found even though only a third of patients received at least $80 \%$ of the target dose for the last three chemotherapy cycles. A more recent study has shown that overall survival is better among stage III colon cancer patients receiving five to seven months of FU than those receiving one to four months of therapy; however, it is not clear that seven months confers a survival advantage over five months, or even whether dose intensity is causally related to the reduced survival in the group who discontinued chemotherapy (Neugut et al. 2006). Therefore, although an insufficient dose or prolonged treatment delays undermine the effectiveness of therapy, it is standard practice to dose-reduce when patients are exhibiting high-grade toxicities without a perceived compromise in treatment outcomes.

Yet, in patients' accounts of dosage reductions or treatment delays, even when they are assured that such treatment changes do not reduce efficacy, they continue to experience doubts; as Joanne noted, "what if it does make a difference?" Once again, this is evidence of a disjuncture between what patients and oncologists know about chemotherapy. Given patient perceptions that side effects equate with efficacy, treatment 
delays or dosage reductions as a result of such side effects could be seen to undermine the very gains such suffering entails. In other words, if suffering is evidence of treatment effectiveness - if, to borrow a popular Nietschzism, "whatever doesn't kill you makes you stronger" - then minimising suffering through dose reductions or treatment delays is likely to be seen as counterproductive. It merely weakens the ability of the drugs to "kill" the cancer cells.

Other drug models patients are familiar with, particularly those relating to antibiotics, may also influence such understandings. Indeed, there is a strong connection between metaphoric understandings of cancer and bacteria. Both are often metaphorically framed as resilient invaders who breach the body's defences - one from within and the other from without (see Martin 1994 for an analysis). For example, one health information website (UW Health 2006) warns: "bacteria are smart. Their goal is to survive, to stay alive". The imagery surrounding cancer is remarkably similar - cancer cells are also anthropomorphised as smart "invaders" skilled at "avoiding detection" and with a unique ability to "become immortal" (see Cold Spring Harbour Laboratory 2006).

Understanding chemotherapy through the metaphoric lens of antibiotics would strengthen the perception that not receiving a 'full' dose is dangerous. Public health campaigns have consistently warned the public that if they do not take the full dosage of antibiotic for an illness, the bacteria can become resistant to the antibiotic: "they become stronger and fight against the medicine" (UW Health 2006). There is striking similarity witnessed in accounts of chemotherapy delays and dosage reductions in light of expressed fears about this making the cancer "grow faster" and the fear of cancer recurrence connected with not receiving a "full dose" - being "short-changed" on the medicine. In this conceptual framework, a reduced dosage is likely to facilitate the cancer recurring more aggressively.

A third and related element of lay understandings of chemotherapy expressed in the support group relates to the difference between oral and intravenous treatment. Although the majority of participants in the group received intravenous chemotherapy, the participants who received oral chemotherapy generally perceived it to be less powerful than the intravenous form. Once again, from a biomedical perspective, oral chemotherapy is not necessarily associated with less 'serious' cancers. Thus, this appears to be yet another instance where side effects become linked with perceived efficacy: a drug that is perceived to produce less side effects is linked with a less powerful treatment. In Ann's case, she determined that her cancer could not have been "as bad" as other stage III cancers in the group, because she received oral rather than intravenous chemotherapy.

These understandings of oral vs. intravenous chemotherapy also appear to relate to broader cultural knowledge highlighted earlier about the different efficacy of injections and pills: we know that injections are more powerful than tablets (Moerman 2002) - an assumption that may also extend to chemotherapy. As Catania and colleagues (2005) point out, "As more drugs are available in oral form, providing good results, assumptions have been made that patients prefer this route of administration. However, this 
hypothesis comes from medical intuition and may not reflect the real attitudes of patients, who may perceive oral drugs as inferior to traditional parenteral chemotherapy" (p. 265). This supposition would seem to contradict the findings of several studies that patients prefer oral chemotherapy over intravenous chemotherapy (see Liu et al. 1997; Borner et al. 2002; Twelves et al. 2006). However, the vast majority of studies on administration preferences have been conducted with advanced cancer patients who are receiving palliative rather than adjuvant chemotherapy, where the intent is no longer to cure the cancer, but to prolong life while minimising side effects.

Another relevant study (Fallowfield et al. 2006) highlights potential demographic differences in cancer patients' attitudes towards injections and pills. The study did not specifically explore chemotherapy preferences but rather preferences for administration of hormone treatments in women with breast cancer. The researchers found that the majority of patients preferred hormone therapy via tablets rather than injections. However, patients educated up to secondary school level were twice as likely to choose injections as those educated beyond this level. Importantly, despite the provision of a scenario describing both treatments as equally effective, patients who preferred injections were significantly more likely to feel that this treatment was more efficacious than patients who preferred tablets (Fallowfield et al. 2006: 208). These findings would suggest that pre-existing cultural assumptions regarding the nature of treatment may play a role in the perceived efficacy of the form that chemotherapy treatment takes - at least for some categories of cancer patient.

Although I have presented these perceptions of chemotherapy as interconnected, there is danger in presenting an overly coherent model of patient understandings of chemotherapy and the suffering associated with it. People's understandings of treatment are not always consistent and patients may hold multiple and even contradictory views. For example, Victoria stated in one breath that she must be cured because she had such an "easy time" of chemotherapy, and then in the next breath asserted that maybe it was "too easy" and her chances of a recurrence were therefore high. Moreover, while I have emphasised the dominance of the idea that suffering during chemotherapy has meaning and value, some patients may reject such equations. Susan DiGiacomo, an anthropologist and cancer survivor, actively campaigned for a lower chemotherapy dose during her treatment. However, her response should be contextualized within her dedication to researching her disease and her ultimately successful struggle to develop a partnership with her doctors. As DiGiacomo later noted, by becoming a collaborator in her treatment she had to give up any certainty about the chances of success: "This was no fiction of participation; it was based on a mutual understanding of chemotherapy as a necessarily and inherently indeterminate process. I knew, and my oncologist knew that I knew, that each one of my treatments was an experiment" (DiGiacomo 1987: 333).

Overall, these findings suggest that the cultural context and meanings of chemotherapy drugs are essential to understanding the treatment decisions and preferences of cancer patients. Although extant studies have highlighted the contextual nature of 'rational' decision-making (Jansen et al. 2001; Duric et al. 2007), patients' treatment decisions are generally understood to result from individual circumstances (e.g. Kiebert et al. 1994; 
Duric et al. 2007) or individual psychologic processes such as coping, adaptation and reduction of cognitive dissonance (e.g. Stiggelbout \& de Haes 2001; Jansen et al. 2001; Jansen et al. 2005). Despite the fact that a large number of cognitive schemata are culturally shared (see Hinton 1996; Mathews 2000), the influence of broader cultural beliefs and their impact on lay models of chemotherapy is rarely taken into consideration.

\section{Study limitations}

Clearly, this study has limitations and the findings of this research require "ethnographic testing" elsewhere (Sanjek 2000: 286). First, it is based only on the depictions of chemotherapy elucidated at a single cancer support group for people with colorectal cancer. Different chemotherapy regimens have developed for different cancer sites, and the standard drugs for adjuvant treatment of colorectal cancer are not necessarily the same as those used to treat other types of cancer. However, as outlined above, there is evidence to suggest that similar lay understandings of chemotherapy are evident amongst patients with other types of cancer.

Another more substantial limitation of the research is that it relies on understandings of chemotherapy elucidated in a support group setting and it is well recognised that such groups attract a very small proportion of people diagnosed with cancer (Mathews 2000; Coreil, Wilke \& Pintado 2004; Herron 2005). Moreover, those patients who do attend support groups are more likely to be white, female and middle class (Mathews 2000; Herron 2005). It is therefore unclear how prevalent such understandings are amongst people of diverse cultural backgrounds or low socio-economic status. ${ }^{4}$ It is also unclear whether these perceptions of chemotherapy reflect pre-existing understandings, or are created through the dynamics of the support group. Mathews' (2000: 399) ethnographic research on a breast cancer support group would suggest that the support group itself "play[s] a crucial role in the development and transmission of synthetic cultural models designed to mediate conflicting beliefs and promote cohesiveness and shared identities among group members".

There is clearly a need for further research into patient perceptions of chemotherapy to ascertain how widespread such understandings are and whether there are gender, class and cultural differences in how patients understand treatment. Research into patient perceptions of radiation would also be useful: how is this less culturally 'loaded' form of therapy understood to operate? Are there parallels with understandings of chemotherapy? Further research into health professionals' understandings of chemotherapy (and the cultural models they, too, use to conceptualise treatment) would also be useful - as well as an examination of areas of divergence and convergence with lay understandings of treatment.

\section{Conclusions}

Chemotherapy is a highly psychologically charged form of treatment, and prefigured by cultural images of pain and suffering. This research has shown that suffering is fundamental to people's preconceptions, understandings and experiences of chemotherapy. Although multiple and often contradictory understandings of chemotherapy and its consequences are evident amongst cancer patients, one dominant 
theme that emerged in the fieldwork is that in attempting to make sense of their cancer and their experience with treatment, support group members have developed understandings of how chemotherapy operates that emphasise the value of suffering as a means through which treatment efficacy can be tracked. This has important implications for the care of such patients.

Healthcare providers often make assumptions about how patients understand treatment based on medical intuition (c.f. Catania et al. 2005). However, what seems 'logical' or 'rational' to a healthcare professional trained in biomedicine is not necessarily logical or rational to a patient (and vice versa). Indeed, this research indicates that the cultural meanings of treatment might lead patients to respond to therapy in seemingly counterintuitive ways: patients who are 'lucky' enough to escape chemotherapy side effects may experience heightened anxiety because of this; patients exhibiting life threatening side effects may be extremely reluctant to reduce their treatment dose; oral chemotherapy may not always be the preferred option amongst patients, despite its 'convenience' and ease of administration. Importantly, these constructions of treatment also appear to be linked with patient assessments of recurrence and people may over- or under-estimate their chance of recurrence based on factors biomedically unrelated to future risk (such as level of side effects, oral vs. IV administration, etc).

\section{Endnotes}

${ }^{1}$ As Moerman (2002: 50) notes, Viagra is a fascinating exception to this general rule. He argues that Viagra's colour demonstrates the "polysemous" nature of blue as a sign: while blue is associated with anxiety, depression and discomfort, it is also associated with sexuality and obscenity - as manifested in terms such as 'blue movie'.

${ }^{2}$ This drop in format did pose some challenges in obtaining informed consent for the study. Prior to conducting the fieldwork, I attended a support group meeting in order to explain the goals of the project and ascertain the group's level of interest in taking part in the study. Based on the enthusiastic response I received, fieldwork was subsequently initiated. When new members were present at meetings, I would approach them beforehand to explain the project and give them written information about the study.

3 For example, an employee from a community-based cancer awareness association sat in on some meetings before my fieldwork began.

${ }^{4}$ It is worth noting that similar discussions of chemotherapy were strikingly absent in a support group for Chinese cancer patients where I have also conducted ethnographic fieldwork.

\section{References}

Abel, G.A., \& Glinert, L.H. (2008). Chemotherapy as language: Sound symbolism in cancer medication names. Social Science \& Medicine, 66: 1863-1869.

Balshem, M. (1991). Cancer, control, and causality: Talking about cancer in a workingclass community. American Ethnologist, 18(1): 152-172.

Beisecker, A.E., Cook, M.R., Ashworth, J., Hayes, J., Brecheisen, M., Helmig, L., Hyland, S., \& Selenke, D. (1997). Side effects of adjuvant chemotherapy: perceptions of node-negative breast cancer patients. Psycho-Oncology, 6: 85-93.

Borner, M.M., Schoffski, P., de Wit, R., Caponigro, F., Comella, G., Sulkes, A., et al. (2002). Patient preference and pharmacokinetics of oral modulated UFT versus 
intravenous fluorouracil and leucovorin: a randomised crossover trial in advanced colorectal cancer. European Journal of Cancer, 38: 349-358.

Breastcancer.org (2008). Myths about chemotherapy. http://www.breastcancer.org/treatment/chemotherapy/chemo.jsp. Accessed 20 August 2008.

Browall, M., Gaston-Johansson, F., \& Danileson, E. (2006). Postmenopausal women with breast cancer. Cancer Nursing, 29(1): 34-42.

Catania, C., Didier, F., Leon, M.E., Sbanooto, A., Mariani, L., Nole, F., et al. (2005). Perception that oral anticancer treatments are less efficacious: Development of a questionnaire to assess the possible prejudices of patients with cancer. Breast Cancer Research \& Treatment, 92: 265-272.

Charles, C., Redko, C., Whelan, T., Gafni, A., \& Reyno, L. (1998). Doing nothing is no choice: Lay constructions of treatment decision-making among women with early-stage breast cancer. Sociology of Health \& Illness, 20(1): 71-95.

Clark, R.A. (1999). Reel oncology: how Hollywood films portray cancer. Cancer Control Journal, 6(5).

Coreil, J., Wilke, J., \& Pintado, I. (2004). Cultural models of illness and recovery in breast cancer support groups. Qualitative Health Research, 14(7): 905-923

Cowley, L., Heyman, B., Stanton, M., \& Milner, S.J. (2000). How women receiving adjuvant chemotherapy for breast cancer cope with their treatment: a risk management perspective. Journal of Advanced Nursing, 31(2): 314-321.

DiGiacomo, S. (1987). Biomedicine as a cultural system: An anthropologist in the Kingdom of the sick. In H. Baer (Ed.), Encounters with biomedicine: Case studies in medical anthropology (pp. 315-346). New York: Gordon \& Breach.

Duric, V.M., Butow, P.N., Sharpe, L., Boyle, F., Beith, B., Wilcken, N.R.C. et al. (2007). Psychosocial factors and patients' preferences for adjuvant chemotherapy in early breast cancer. Psycho-Oncology, 16: 48-59.

Etkin, Nina L. \& Tan, Michael L. (1994). Medicines: meanings and contexts. Amsterdam: University of Amsterdam Press.

Etkin, N.L., Ross, P.J., \& Muazzamu, I. (1999). The rational basis of 'irrational' drug use: Pharmaceuticals in the context of development. In R.A. Hahn (Ed.), Anthropology in public health: Bridging differences in culture and society (pp. 165-181). New York: Oxford University Press. 
Fallowfield, L., Atkins, L., Catt, S., Cox, A., Coxon, C., Langridge, C., Morris, R., \& Price, M. (2006). Patients' preference for administration of endocrine treatments by injection or tablets: results from a study of women with breast cancer. Annals of Oncology, 17: 205-210.

Frith, H., \& Harcourt, D. (2007). Using photographs to capture women's experiences of chemotherapy: Reflecting on the method. Qualitative Health Research, 17: 1340-1350.

Frith, H., Harcourt, D., \& Fussell, A. (2007). Anticipating an altered appearance: Women undergoing chemotherapy treatment for breast cancer. European Journal of Oncology Nursing, 11: 385-391.

Gibbs Jr, R.W. \& Frank, H. (2002). Embodied metaphor in women's narratives about their experiences with cancer. Health Communication, 14(2): 139-165.

Good, M-J. V.,Good, B.J., Schaffer, C., \& Lind, S.E. (1990). American oncology and the discourse on hope. Culture, Medicine \& Psychiatry, 14: 59-79.

Greer, S. (1984). The psychological dimension in cancer treatment. Social Science \& Medicine, 18(4): 345-349.

Gurney, H. (2002). How to calculate the dose of chemotherapy. British Journal of Cancer, 86: 1297-1302.

Haydon, A. (2003). Adjuvant chemotherapy in colon cancer: what is the evidence? Internal Medicine Journal, 33: 119-124.

Herron, L-M. (2005). Building effective cancer support groups: Report to the Department of Health and Ageing. Sydney: Cancer Council Australia

Hinton, A. (1996). Agents of death: explaining the Cambodian genocide in terms of cognitive dissonance. American Anthropologist, 98: 818-831.

Cold Spring Harbour Laboratory (2006). Inside cancer. http://www.insidecancer.org/ [Accessed 29 April 2008].

Jansen, S.J.T., Kievit, J., Nooij, M.A., de Haes, J.C.J.M., Overpelt, I.M.E., van Slooten, H., Maartense, E., \& Stiggelbout, A.M. (2001). Patients' preferences for adjuvant chemotherapy in early-stage breast cancer: is treatment worthwhile? British Journal of Cancer, 84(12): 1577-1585.

Jansen, S.J.T., Otten, W., Baas-Thijssen, M.C.M., van de Velde, C.J.H., Nortier, J.W.R., \& Stiggelbout, A.M. (2005). Explaining differences in attitude toward adjuvant chemotherapy between experienced and inexperienced breast cancer patients. Journal of Clinical Oncology, 23(27): 6623-6630. 
Kiebert, G.M., Stiggelbout, A.M., Kievett, J., Leer, J-W.H., van de Velde, C.J.H., \& de Haes, J.C.J.M. (1994). Choices in oncology: Factors that influence patients' treatment preferences. Quality of Life Research, 3(3): 175-182.

Kleinman, A.M. (1988). The illness narratives: Suffering, healing and the human condition. New York: Basic Books.

Labianca, R., Milesi, L., Mosconi, S., Pessi, M.A., Beretta, G.D., \& Quadri, A. (2007). The role of adjuvant chemotherapy in colon cancer. Surgical Oncology, 16(Suppl 1): S93-96.

Lemare, F., Mateus, C., Camps, S., Montheil, V., Henguelle, E., Cacheux, W., et al. (2007). Chemotherapy in non-selected elderly patients: Factors influencing dose-intensity and toxicity. Journal of Clinical Oncology, 25(18S):

Lindley, C., McCune, J.S., Thomason, T.E., Lauder, D., Sauls, A., Adkins, S., \& Sawyer, W.T. (1999) Perception of chemotherapy side effects: Cancer versus noncancer patients. Cancer Practice, 7(2): 59-65.

Liu, G., Franssen, E., Fitch, M.I., \& Warner, E. (1997). Patient Preferences for Oral Versus Intravenous Palliative Chemotherapy. Journal of Clinical Oncology, 15(1): 110115.

Martin, Emily (1994). Flexible bodies: Tracking immunity in American culture from the days of polio to the age of AIDS. Boston: Beacon Press.

Mathews, Holly F. (2000). Negotiating cultural consensus in a breast cancer self-help group. Medical Anthropology Quarterly, 14(3): 394-413

Maughan, T.S. (2001). Adjuvant chemotherapy for colorectal cancer. British Journal of Cancer, 85(10): 1422-1424.

Moerman, Daniel (2002). Meaning, medicine and the 'placebo effect'. Cambridge: Cambridge University Press.

Moore, R. (2001). African American women and breast cancer. Cancer Nursing, 24(1): $35-43$.

Nichter, Mark \& Nichter, Mimi (1996). Anthropology and international health: Asian case studies. England: Routledge.

Nerenz, D.R., Leventhal, H., \& Love, R.R. (1982). Emotional distress during chemotherapy. Cancer, 50: 1020-1027.

Neugut, A.I., Matasar, M., Wang, X., McBride, R., Jacobson, J.S., Tsai, W-Y., Grann, V.R., \& Hershman, D.L. (2006). Duration of adjuvant chemotherapy for colon cancer and survival among the elderly. Journal of Clinical Oncology, 24(15): 2368-2375. 
O’Connell, M.J., Mailliard, J.A., Kahn, M.J., Macdonald, J.S., Haller, D.G., Mayer, R.J., \& Wieand, H.S. (1997). Controlled trial of Fluorouracil and lose-dose Leucovorin given for 6 months as posteroperative adjuvant therapy for colon cancer. Journal of Clinical Oncology, 15(1): 246-250.

Penson, P.T.; Schapira, L.; Daniels, K.J.; Chabner, B.A. \& Lynch Jr, T.J. (2004). Cancer as metaphor, The Oncologist, 9: 708-716.

Repetto, L. (2003). Greater risks of chemotherapy toxicity in elderly patients with cancer. Journal of Supportive Oncology, 1(4 Suppl 2):18-24.

Richer, M-C., \& Ezer, H. (2002). Living in it, living with it, and moving on: dimensions of meaning during chemotherapy. Oncology Nursing Forum, 29(1): 113-119.

Rieff, D. (2008). Swimming in a sea of death: a son's memoir. New York: Simon \& Schuster.

Rosman, S. (2004). Cancer and stigma: experience of patients with chemotherapyinduced alopecia. Patient Education \& Counseling, 52: 333-339.

Saillant, F. (1990). Discourse, knowledge and experience of cancer: a life story. Culture, Medicine \& Psychiatry, 14: 81-104.

Sanjek, R. (2000). Keeping ethnography alive in an urbanizing world. Human Organization, 59(3): 280-288.

Sinding, C., \& Gray, R. (2005). Active aging—spunky survivorship? Discourses and experiences of the years beyond breast cancer. Journal of Aging Studies, 19: 147-161.

Skott, C. (2002). Expressive metaphors in cancer narratives. Cancer Nursing, 25(3): 230-235.

Stiggelbout, A.M., \& de Haes, J.C.J.M. (2001). Patient preference for cancer therapy: An Overview of measurement approaches. Journal of Clinical Oncology, 19(1): 220-230.

Sontag, S. (1977/1990). Illness as metaphor and AIDS and its metaphors. New York: Picador.

Stoller, P. (2004). Stranger in the village of the sick: a memoir of cancer, sorcery, and healing. Boston: Beacon Press.

Sun, W., \& Haller, D.G. (2005). Adjuvant therapy of colon cancer. Seminars in Oncology, 32(1): 95-102. 
Twelves, C., Gollins, S., Grieve, R., \& Samuel, L. (2006). A randomised cross-over trial comparing patient preference for oral capecitabine and 5-fluorouracil/leucovorin regimens in patients with advanced colorectal cancer. Annals of Oncology, 17: 329-345.

University of Wisconsin Health (2008). Health information: be wise about antibiotics. http://www.uwhealth.org/servlet/Satellite?cid=1113313581133\&pagename=B EXTRAN ET HEALTH INFORMATION\%2FFlexMember\%2FShow Public HFFY\&c=FlexGro up [accessed 17 April 2008]. 